\title{
Erratum to: Automatic determination of cardiovascular risk by CT attenuation correction maps in Rb-82 PET/CT
}

\author{
Ivana Išgum, PhD, ${ }^{\mathrm{a}} \mathrm{Bob} \mathrm{D}$. de Vos, $\mathrm{MSc},{ }^{\mathrm{a}}$ Jelmer $\mathrm{M}$. Wolterink, $\mathrm{MSc}{ }^{\mathrm{a}}$ \\ Damini Dey, PhD, ${ }^{\mathrm{b}}$ Daniel S. Berman, MD, ${ }^{\mathrm{b}}$ Mathieu Rubeaux, PhD, ${ }^{\mathrm{b}}$ \\ Tim Leiner, $\mathrm{MD}, \mathrm{PhD},{ }^{\mathrm{c}}$ and Piotr J. Slomka, $\mathrm{PhD}^{\mathrm{b}}$ \\ a Image Sciences Institute, University Medical Center Utrecht, Utrecht, The Netherlands \\ b Departments of Imaging and Medicine, Cedars-Sinai Medical Center, Los Angeles, CA \\ c Department of Radiology, University Medical Center Utrecht, Utrecht, The Netherlands
}

doi: $10.1007 / \mathrm{s} 12350-017-0946-4$

\section{ERRATUM TO: J NUCL CARDIOL} DOI 10.1007/S1 2350-017-0866-3

Regrettably an error was introduced in Table 3 during the article's production. The very first cell (row:
Very low 0; column: Very low) should read '12' and not '21' as originally published. The corrected Table 3 appears below.

Table 3. Manual CAC scoring in CSCT vs (a) manual and (b) automatic CAC scoring in CTAC at rest

\begin{tabular}{lcccrc}
\hline & Very low & Low & Intermediate & High & Very high \\
\hline Very low 0 & 12 & 1 & 0 & 0 & 0 \\
Low 1-10 & 5 & 0 & 1 & 0 & 0 \\
Intermediate 11-100 & 0 & 2 & 6 & 4 & 0 \\
High 101-400 & 0 & 0 & 3 & 25 & 7 \\
Very high $>$ 400 & 0 & 0 & 1 & 6 & 55 \\
\hline & Very low & Low & Intermediate & High & Very high \\
\hline Very low 0 & 13 & 0 & 0 & 0 & 0 \\
Low 1-10 & 5 & 0 & 1 & 0 & 0 \\
Intermediate 11-100 & 4 & 0 & 3 & 5 & 0 \\
High 101-400 & 2 & 0 & 2 & 8 & 9 \\
Very high $>$ 400 & 0 & 0 & 1 & 53 \\
\hline
\end{tabular}

Cardiovascular risk categories based on the Agatston score (0,1-10, 11-100, 101-400, >400) assigned to a patient by the manual scoring in CSCT (rows) and (a) manual and (b) automatic scoring in CTAC scans acquired at rest (columns) taking different ranges of Agatston scores between CSCT and CTAC scan into account

The online version of the original article can be found under doi: 10.1007/s12350-017-0866-3.

Reprint requests: Ivana Išgum, PhD, Image Sciences Institute, University Medical Center Utrecht, Utrecht, The Netherlands; i.isgum@umcutrecht.nl

J Nucl Cardiol 2018;25:2143.

$1071-3581 / \$ 34.00$

Copyright (C) 2017 American Society of Nuclear Cardiology. 